\title{
Changing the method of compaction of autoclaved building materials modified by diabase and barite aggregate.
}

\author{
Katarzyna Komisarczyk*, Anna Stępień and Ryszard Dachowski \\ Faculty of Civil Engineering and Architecture, Department of Building and Architecture, Kielce \\ University of Technology, Kielce
}

\begin{abstract}
The traditional way of producing sand-lime products is connected with the use of three basic raw materials i.e. quartz sand of natural origin, water and quicklime ground lime. During hydrothermal treatment in an autoclave, chemical reactions take place between the calcium and silicon ions. As a result of these reactions, the products are created that provide advantageous appropriable traits. In order to improve the durability attributes of the discussed products, diabase and barite aggregate was introduced into the raw material mass. In addition, the change in the densification method of the silicate mixture was applied. Layering was replaced instead of traditional pressing. The article describes sand-lime products modified with diabase and barite aggregate in an amount up to $15 \%$ by weight. Two methods of thickening the sand-lime mixture were used: pressing and layering. The change of the applied technology significantly influences, among others for water absorption. The best result was obtained using $5 \%$ and $10 \%$ modifiers. Modification with $5 \%$ content of diabase aggregate and $5 \%$ content of barite aggregate increases the strength by over $60 \%$ in relation to the reference sample. The obtained properties are reflected in the image of the microstructure examined by means of the scanning electron microscope. In the sand- lime products, both traditional and modified with diabase and barite aggregates, the C-S-H phase and tobermorite is present. These phases are characteristic for autoclaved products, although depending on the method of thickening occur in varying degrees and intensities.
\end{abstract}

\section{Introduction}

Concept of ecological construction was born in the United States in the 70s of twentieth century during oil crisis. American designers and scientists noticed the need of building more energy-efficient objects and introducing environmentally friendly building processes. The growth of importance of ecology in respect of construction and also the implementation of strategy of balanced construction caused that the search for new materials and technological solutions that reduce energy demand became necessary [1].

The change of composition to underestimated/stored components with similar properties

* Corresponding author: komisarczyk.kasia@gmail.com 
and simultaneously appropriate selection of pressure and conditions of autoclaving can contribute to beneficial changes.

According to opinions of specialists such effect can be achieved in several ways. One of them is the interference in the course of chemical processes occurring during hydrothermal treatment in the autoclave. The changes can be connected as well with the changes of the conditions of synthesis, i. e. time of autoclaving and temperature of autoclaving, pressure of saturated water vapour, as with the introduction of mineral additives being carriers of alien ions to reaction system [2-4]. The application of additives with pozzolanic and/or hydraulic properties can have two effects. On the one hand it can cause the creation of larger amount of amorphous phase C-S-H in initial stage of reaction between ions of calcium and silicon $[5,6]$. On the other hand it can accelerate the transformation of amorphous phase C-S-H into crystalline products: tobermorite $\mathrm{C}_{5} \mathrm{~S}_{6} \mathrm{H}_{5}$ or xonotlite $\mathrm{C}_{6} \mathrm{~S}_{6} \mathrm{H}$ [7]. It results from conducted researches that the introduction of sulphate ions or alkalis to limestone and sand mass causes higher degree of reactivity of initial materials, what results in the creation of significant number of products of synthesis, which are directly responsible for the strength of autoclaved materials.

Another way of modification of raw material composition of production mass, which influences favourably the strength of finished product is the application of such additive, which will influence the creation of additional phases. The researches up to now conducted by Z. Pytel and J. Małolepszy showed that the role of such mineral additive can be played by ground limestone [8] or limestone dust arising as by-product in industrial plants producing burnt lime or carbonate sorbents. This raw material, which is introduced in appropriate quantity into raw material mass at the stage of formation of semi-finished products plays the role of plasticizer. In this way it ensures required rheological properties. During hydrothermal treatment in the autoclave it can create mineral phase in the form of scawtite, the presence of which influences favourably the strength characteristics of finished products $[9,10]$.

Next interference can be directed towards appropriate modification of raw material composition, causing favourable change of the curve of granulation. Appropriate selection of the resultant of the curve of granulation allows to press of semi-finished products with higher degree of compaction, what in consequence will cause obtaining less porous products with lower absorptivity, but with higher density and higher strength. The increase of the degree of compaction connected with the increase of the pressure of pressing (at the stage of formation) can cause cracking grains of sand. However beneficial effect can be achieved by the introduction of simple technological procedure consisting in replacing traditional pressing with well-known from the literature technologies of vibration, vibro-pressing or layered pressing. It is assumed that such modifications will have beneficial influence over structure and microstructure, determining the properties of final products. Research conducted at PSK can prove that the application of heavy aggregates, among others graphite, basalt and barite can cause the increase of density and strength, and consequently the increase of acoustic insulating properties [11-13]. In turn the application of light aggregates(ashoporite) in raw material mixture led to the decrease of the density of finished products and simultaneous improvement of the parameter of thermal insulation.

Beginning from mathematical planning of the experiment the article presents the results of the research of bifactor incomplete experiment. Modifiers in the form of diabase aggregate and barite aggregate were introduced to raw material mass. Besides traditional pressing, technology of layered pressing were applied. Therefore presented in the article researches include the analysis of technological processes leading to the increase of degree of compaction and their influence over physical-mechanical-chemical properties.

The selection of proper components of raw material mass is extremely fundamental. In the experiment unslaked burnt lime produced by Trzuskawica joint stock company, meeting all normative requirements, was used. Water comes from the water intake 
in Krasocin. It meets all requirements for water which can be applied for the production of lime and sand products. While quartz sand is characterized by constant curve of granulation without distinct dominance of any granular fraction. It is small-grained sand. Granulation, in which the proportion of granular fractions is following: $2.5-0.5 \mathrm{~mm}$ to $30 \%$ and $0.5-0.05 \mathrm{~mm}$ at least $65 \%$ is recognized as appropriate granulation for the production of lime and sand products [2,3]. Additionally the requirements are applied in respect of the shape of grains. These grains, which are the most suitable, are characterized by sharp or dull corners with sharply shaped large concavities. Diabase aggregate used in objective researches comes from the "Niedźwiedzia Góra" mine in Little Poland. In international classification for volcanic rocks the position of variants of rock from Niedźwiedzia Góra places them on the border of basalts and andesites. In microscopic image of the diabase full crystalline structure is visible and the texture is compact and disorderly. The main component of the rock are plagioclases, pyroxenes, orthoclases and olivines. The density of particles of the diabase varies from 2900 to $3100 \mathrm{~kg} / \mathrm{m} 3$, while it is about 2700 in natural sand [14]. The hardness of minerals of the diabase in Mohs scale is about 7, what is slightly higher value than in the case of natural sand. In objective researches diabase aggregate with fraction of 0 $2 \mathrm{~mm}$ was used according to guidelines. The diabase is used in earthworks, as raw material in asphalt industry and due to its properties perfectly storing heat and resistant to high temperature is used as the rock in Finnish sauna.

Addition of barite aggregate significantly increase compression strengths of materials. Additionally it led to the increase of the density of autoclaved brick and in consequence it influenced beneficially acoustic insulation. The application of barite aggregate in autoclaved materials influences also the enhancement of radiological resistance, which is already well-known in technology of concrete. Barite concrete is the protection from ionization radiation, therefore it is applied for concreting walls and ceilings of protective rooms in scientific and research laboratories, oncology centers and nuclear power plants [15].

\section{Experimental}

According to adopted conception of conducting researches particular series of samples of silicate materials, as well reference samples as experimental samples, were obtained in fixed and repeatable way. In the first place respective quantities of particular components wre weighed out. Diabase aggregate were added in turn in the amount of 2,5,5,5,10 and $15 \%$ in relation to total content of other components. Identical proportions were applied with dosing barite aggregate Table 1 . Water was added in the quantity, which was necessary to obtain moulding humidity of masses at the level of $6 \%$.

Table 1. Amount of modifiers

\begin{tabular}{c|c|c} 
Total amount of additive [\%] & Amount of diabase [\%] & Amount of barite [\%] \\
\hline 5 & 2,5 & 2,5 \\
\hline 10 & 5 & 5 \\
\hline 20 & 10 & 10 \\
\hline 30 & 15 & 15
\end{tabular}

So prepared masses were laid into steel, three-field moulds, thanks to which samples in the form of beams with dimensions $40 \times 40 \times 160 \mathrm{~mm}$ (height $\times$ width $\times$ length) were obtained (Fig. 1). In the first part of the experiment forming samples was carried out using hydraulic press with the method of double-sided single-stage pressing. In the second part samples were pressed at three stages. Directly after completion of the process of forming samples were hydrothermally treated in industrial autoclaves. The conditions 
of hydrothermal treatment were following: pressure of saturated water vapour 1.6 $\mathrm{MPa}$, temperature of water vapour $203^{\circ} \mathrm{C}$, time of autoclaving 9.5 hours.

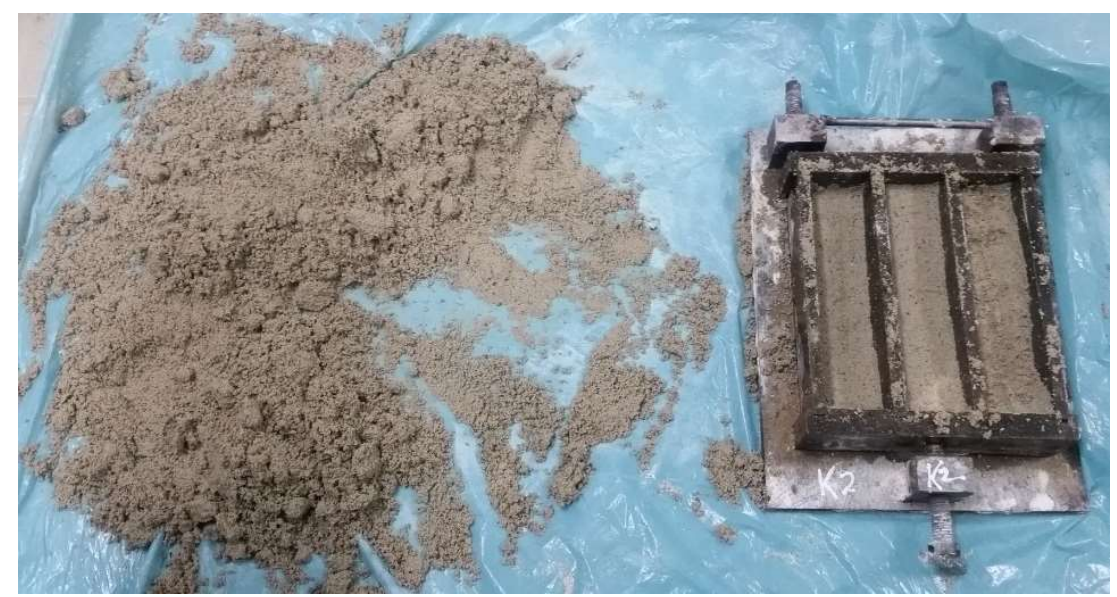

Fig. 1. Laying raw material mass.

\section{Testing methods}

The quality of obtained particular series of samples of autoclaved materials in presented way was assessed on the basis of the results of basic tests of performance parameters. The resistance to compression was tested according to PN-EN 772-1 [16] standard, net/gross density in dry state according to PN-EN 772-13 [17] standard. Absorptivity of finished lime and sand samples was determined. Key importance for more complete characterization of obtained materials had the results of tests of microstructure, which were conducted with the method of scanning microscopy (SEM-type Quanta 250 FEG) together with the analysis of chemical composition in micro-areas (EDS).

\section{Results and discussion}

In further part of the article, thought abbreviations were introduced: P-technology of singlestage pressing, WP-technology of layered, three-stage pressing of raw material masses.

\subsection{Physical properties}

Well-known dependence of density and strength of materials is reflected in the results of conducted tests on limestone and sand samples. Then the higher density of materials, the higher their resistance to compression (Fig. 2, Fig. 3) In each of compared cases technology of layered pressing, according to assumptions, contributes to the increase of the strength in relation to technology of traditional pressing. In WP technology, modification of $5 \%$ in the range of content of diabase aggregate and $5 \%$ in the range of content of barite aggregate increases the strength by over $60 \%$ in relation to reference sample. Therefore application of small quantity of additives (up to 10\%) allows to achieve the strength at the level of over $47 \mathrm{MPa}$.

Despite the application of identical raw material composition the change of technology of compaction influences significantly the absorptivity. In WD technology, regardless 
of the number of applied modifiers, the decrease of absorptivity was noted in relation to reference sample. Addition of aggregates in the amount of $10 \%$ in relation to total content of other components decreases absorptivity to $12,3 \%$ (Fig 4).

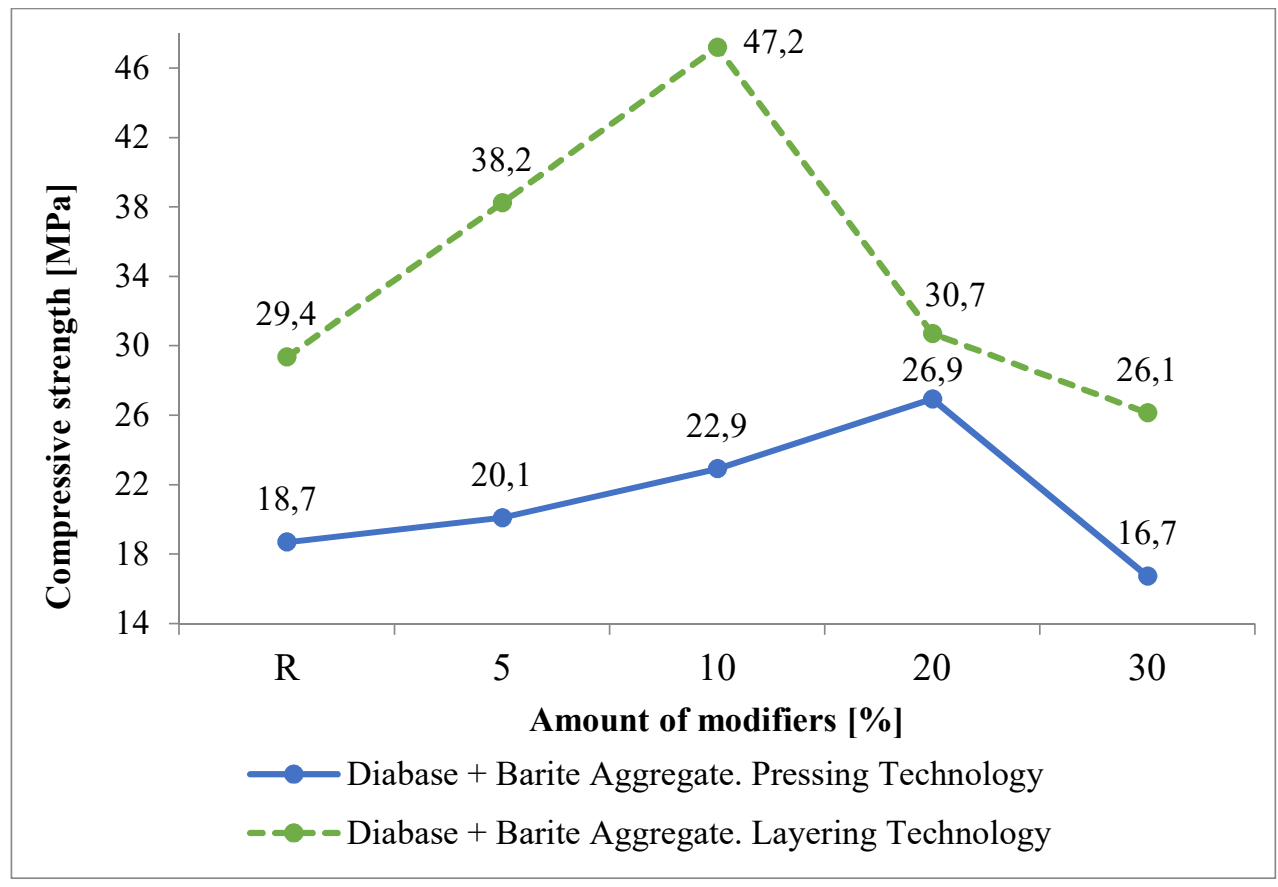

Fig. 2. Compressive strentgh of sand- lime products.

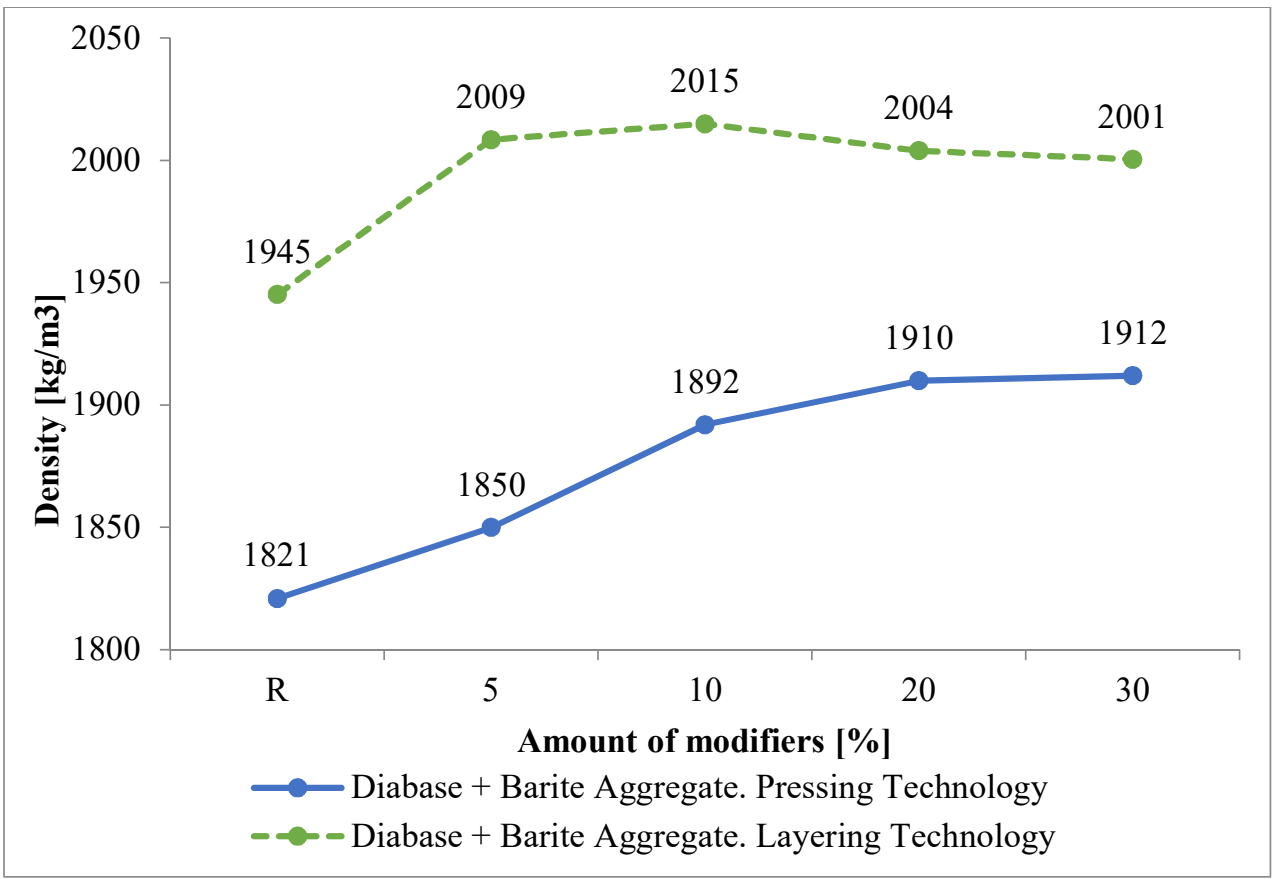

Fig. 3. Density of sand- lime products. 


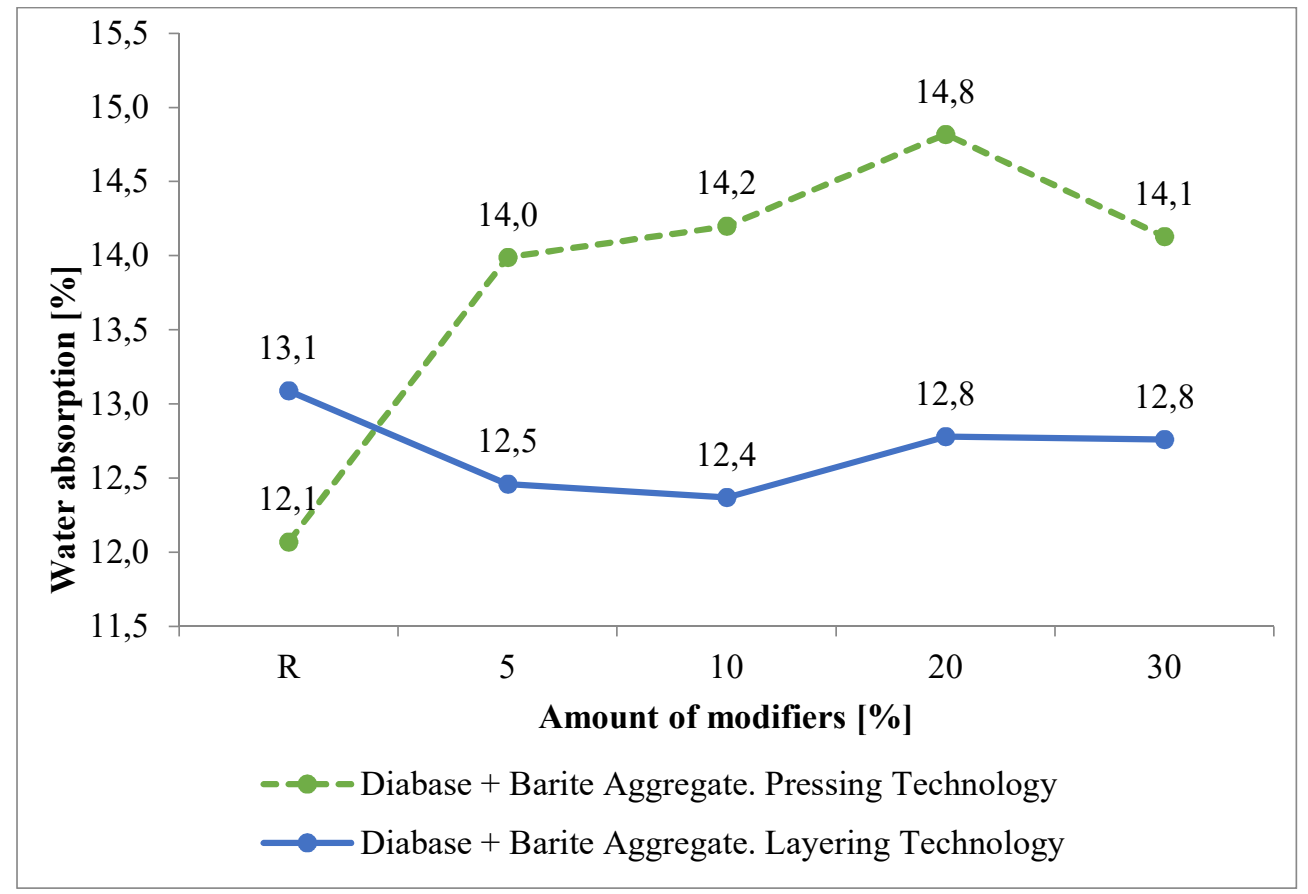

Fig. 4. Water absorption of sand- lime products. 


\subsection{Microstructure}

It results from conducted analysis that in reference samples made as well in technology of pressing as in technology of layered laying amorphous phase C-S-H (Fig. 5) arises in the zone near the surface of aggregate, what in both cases is confirmed by conducted EDS analysis (Fig. 6).

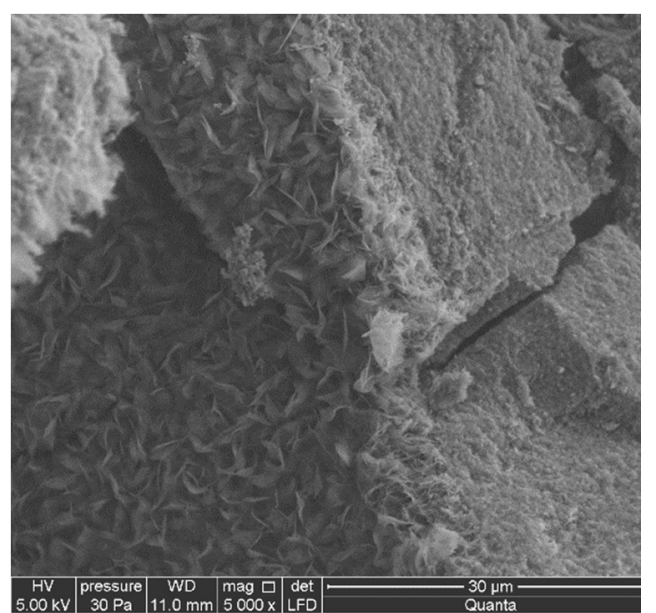

Fig. 5. Microstructure of reference sample.

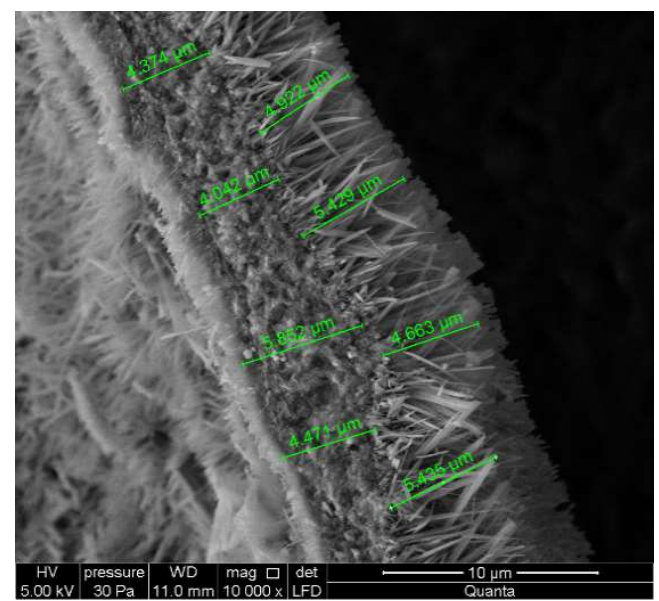

Fig. 7. Microstructure. Pressing technology.

\section{$2,5 \% \mathrm{~B}$ and $2,5 \% \mathrm{D}$.}

Comparing the images of microstructure of samples of limestone and sand materials, differences in the morphology of arising phases can be indicated. The C-S-H phase, which is basic product of synthesis arising in hydrothermal conditions in reference sample takes spongy form. In P technology the increase of quantity of additive from 5 to $20 \%$ causes the change of the size of crystals of tobermorite phase. (Fig. 7, Fig. 8). In WP technology in samples with content of $2.5 \% \mathrm{D}$ and $2.5 \% \mathrm{~B}$ tobermorite phase takes the form of thick, short plates (Fig. 9). As content of additives increases, tobermorite changes into intensely thickened, long, irregular bands with different width (Fig. 10). 


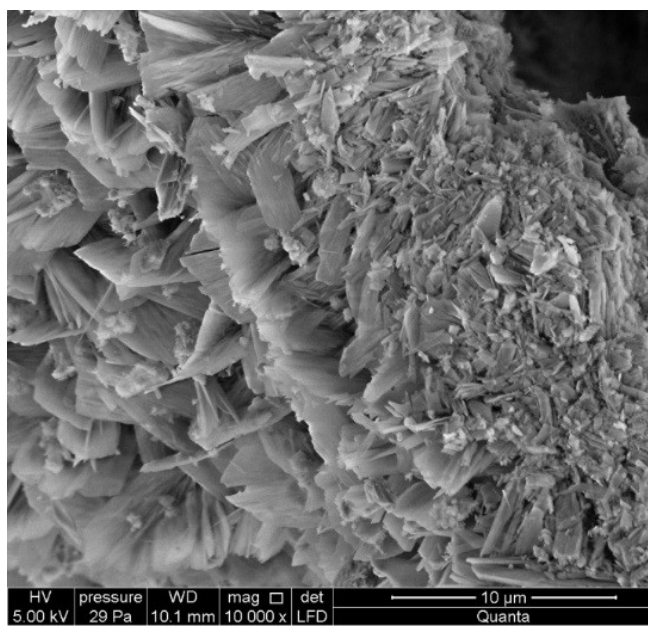

Fig. 9. Microstructure. Layering technology. Sample with amount of 2,5\% barite and 2,5\% diabase aggregate.

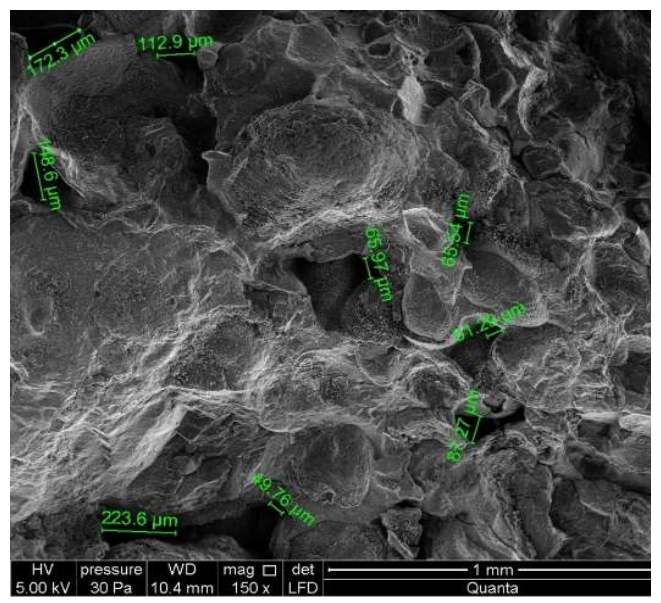

Fig. 11. Microstructure. Layering technology. Sample with amount of 5\% barite and 5\% diabase aggregate.

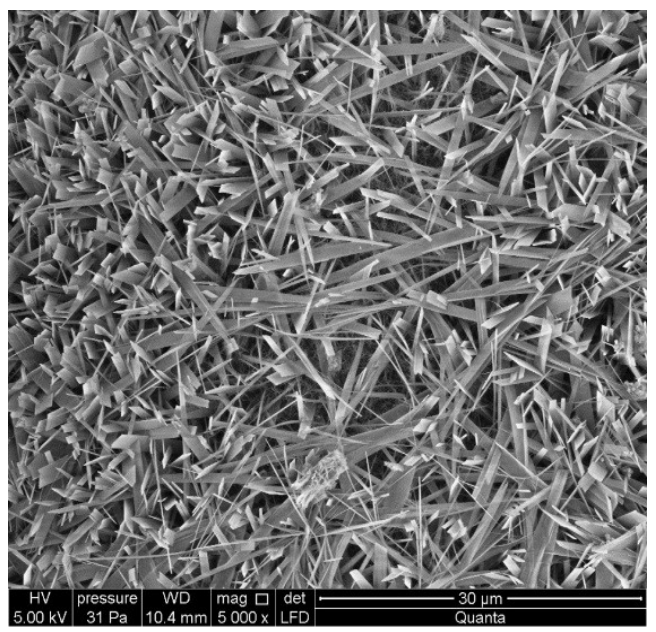

Fig. 10. Microstructure. Layering technology. Sample with amount of 5\% barite and 5\% diabase aggregate.

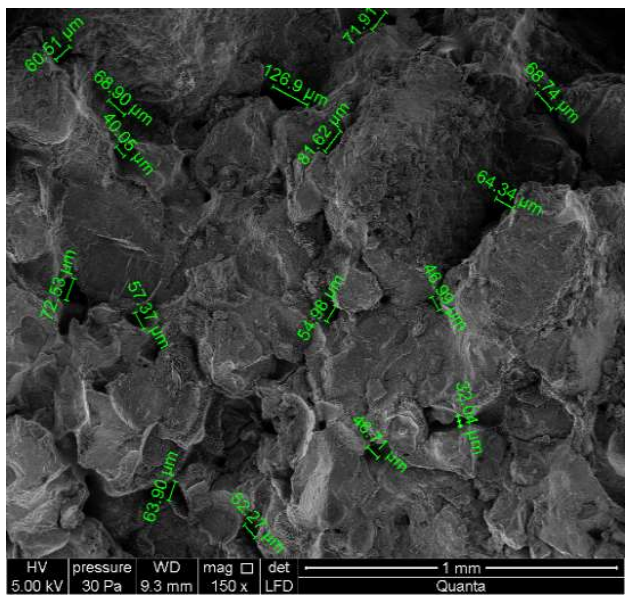

Fig. 12. Microstructure. Pressing technology. Sample with amount of $5 \%$ barite and $5 \%$ diabase aggregate.

The change of the way of formation of raw material mixture influences higher degree of compaction of finished products and also the change of size and distribution of pores (Fig. 11, Fig. 12).

\section{Conclusion}

Conducted researches allow to formulate following conclusions:

-the change of the way of compaction of mixture influences significantly absorptivity and resistance to compression,

-in technology of layered pressing $10 \%$ of modifier (5\% of diabase and $5 \%$ of barite) increases resistance to compression by over $60 \%$ in relation to reference sample, -in the image of microstructure distinct differences in relation to reference samples are not observed, however the morphology of C-S-H phase and tobermorite changes. 


\section{References}

1. B. Fiedor Econ. Cri. Ver. Cri. Of Econ. Sci.453-465 (2010)

2. Z. Pytel, The effect of mineral additives on the properties of calcium silicate bricks Cer. 120 18-29 (2016)

3. Z. Pytel, Modification of the phase composition and microstructure of autoclaved sandlime brick Cer.116 39-50 (2014)

4. J. Dobek, Sand-lime brick. Raw material and technological process Build. and Arch. 1025 (1955)

5. J. Małolepszy, Basics of building materials technology and research methods 82-91 (2013)

6. Z. Pytel J. Małolepszy, The structure and microstructure of autoclaved materials modified by pozzolanic material admixtures Con. Pro. 3 1640-1649 (2003)

7. W. Nocun- Wczelik Structure and the most important properties selected hydrated calcium silicates, Cer. 59 (1991)

8. Z. Pytel, The influence of ground limestone on the properties of autoclaved sand-lime Cer. 91, 2 (2005)

9. W. Kurdowski, M. Pilch, On the mechanism of scawtite formation, Proc. in the $9^{\text {th }}$ Inter. Congr. Chem. Cem. IV 170-174 (1993)

10. Z. Pytel, Synthesis of scavite in hydrothermal conditions Cem. Lim. Conc. XIII/LXXV 6 (2008)

11. A. Stępień, The impact of glass additives on the functional and microstructural properties of sand-lime bricks Inter. Jou. Civ. and Envi. Eng. 4, 3 (2017)

12. A. Stępien, The impact of barium sulfate on the microstructural and mechanical properties of autoclaved silicate products Envi. Eng. 9, 1-6 (2014)

13. R. Dachowski, A. Stępien, Impact of modification of sand-lime mass with organic compounds on the microstructure and mechanical features of silicate bricks Envi. Eng. (2014)

14. A. Wolska, Petrographical And Chemical Composition Of The Diabase From The Niedźwiedzia Góra Geol. Surv. 32 391-396 (1984)

15. A. M. Brandt, Concrete as a shielding material in nuclear energy constructions Cem. Lim. Conc. (2012)

16. PN-EN 772-1 Test methods for masonry components part 1 (2001)

17. PN-EN 772-13 Test methods for masonry components part 13 (2001) 